\title{
Key drivers of EU budget allocation: Does power
}

\section{matter?}

\author{
Vera Zaporozhets* $\quad$ María García-Valiñas ${ }^{\dagger}$ Sascha Kurz ${ }^{\ddagger}$
}

\begin{abstract}
We examine the determinants of the EU budget expenditures allocation among different countries. In line with earlier literature, we consider two alternative explanations for the EU budget distribution: political power vs. "needs view." Extending the original data set from Kauppi and Widgrén (2004), we analyze the robustness of their predictions when applying a different measure of power and more sophisticated econometric techniques. We conclude that the nucleolus is a good alternative to the Shapley-Shubik index in distributive situations such as the case of EU budget allocation. Our results also show that when explaining budget shares, the relative weight of political power based on the nucleolus is lower than the predictions of previous studies based on the Shapley-Shubik index.
\end{abstract}

Keywords: EU policies, budget allocation, political power, nucleolus, ShapleyShubik index.

JEL codes: D72, D78, H61, O52

${ }^{*}$ Corresponding Author. Toulouse School of Economics (LERNA, INRA), e-mail: vzaporoz@toulouse.inra.fr

${ }^{\dagger}$ University of Oviedo

$\ddagger$ University of Bayreuth 


\section{Introduction}

In 2013, the European Union (EU) expenditure budget was around 149 billion, with cohesion, and agricultural and environmental resources being the primary EU policies, with shares of $46.8 \%$ and $39.8 \%$ respectively. Due to the magnitude of these figures, the distribution of the EU budget among different countries is a crucial issue to analyze. In particular, we focus on the relative weights of different factors when explaining the budget shares corresponding to each EU member.

Previous literature (Courchene et al., 1993; Anderson and Tyers, 1995; Tangermann, 1997; Kandogan, 2000; Kauppi and Widgrén, 2004, 2007) has tested two alternative explanations of the EU budget distribution across the members states. The first is a "needs view," which states that the budget allocation is determined by the principles of solidarity. According to this hypothesis, the countries with a high agriculture sector weighting and/or a relatively worse economic situation emerge as the major recipients of the EU budget. In fact, some of the previous studies have focused exclusively on this explanation (Courchene et al., 1993; Anderson and Tyers, 1995; Tangermann, 1997). The second explanation is that budget allocation across the members is reflected by the distribution of their political power. Thus, those countries with more power in the allocation process could receive larger shares of the budget.

Some studies combine both: needs and the power views (Kandogan, 2000; Kauppi and Widgrén 2004, 2007; Aksoy, 2010). Thus, empirical analysis by Kauppi and Widgrén (2004) shows the strong prevalence of political power motives.

Their results indicate that political power has much higher weight than needs when determining the allocation of budget expenditures among EU member states.

The overall purpose of this paper is to reconsider the analysis of Kauppi and Widgrén (2004) and to challenge their conclusions. To do so, we extend the original data set (1976-2001) up to 2012 and introduce alternative model specifications. In contrast to the existing studies which have used the Shapley-Shubik index as a measure of political power, we employ a different measure; the nucleolus. It has been argued that the 
nucleolus is an appropriate power measure in distributive situations as well as a good alternative to traditional measures, such as the Shapley-Shubik index 1 Moreover, we apply sophisticated econometric techniques, which are more suitable for the analysis.

The paper is structured as follows. Section 2 provides a brief introduction on the EU budget, including the processes of designing and allocating EU expenditures and revenues. In Section 3, we discuss the theoretical properties of two different power indices. Specifically, we highlight the advantages of the nucleolus over other indices in distributive situations, such as the EU budget allocation. Finally, in Section 4, we specify a simple empirical model in order to determine the key drivers for EU budget allocation. Section 5 concludes with a summary of the main findings in addition to some policy implications.

\section{EU budget: procedure and evolution}

As mentioned in the Introduction, the EU expenditure budget represents a significant amount of resources. In 2013, total expenditures were 148,468 million. Although this is not a substantial amount in relative terms (just 1.13\% of the EU-27 Gross National Income, GNI), some crucial policies were developed using EU funding. Examples are the Common Agricultural Policy (now part of a more extensive section on the preservation and management of natural resources) or several policies oriented towards the economic development of some target regions (cohesion and competitiveness policies). Each EU member also has to contribute to the EU budget, by means of GNI-based resources (74.3\%), VAT-based own resources (9.5\%), and traditional own resources (TOR, 10.4\%).

In 1976, the EU expenditure budget amounted to 7,563 million. In the last decades, the EU budget has been growing 2 This increasing path can be interpreted as a snap

${ }^{1}$ For example, Montero (2005), Montero (2013) and Le Breton et al. (2012) among others.

${ }^{2}$ Figures on the EU budget are available at http://ec.europa.eu/budget/figures/index_n.cfm. 
that simultaneously captures the history of EU integration and several budgetary reforms. Regarding the enlargement process, there are some significant facts which could have an impact on the evolution of the EU expenditures. In 1986, the EU grew from 10 to 12 countries, through the integration of Portugal and Spain as new members. Similarly, Austria, Finland and Sweden joined the EU/EC in 1995. Furthermore, one of the largest phases of expansion occurred in 2004, when the EU grew from 15 to 25 member countries 3

Successive EU reforms have changed the structure of the budget. In this respect there are some facts that are worth mentioning. At the Brussels European Council in February 1988, a political agreement on doubling, in real terms, the budget of the Structural Funds between 1987 and 1993 was reached. Subsequently, Member States agreed at the Edinburgh European Council in December 1992 that the budget for structural operations would be further increased, specifically for the cohesion countries (Greece, Ireland, Portugal and Spain). Also in Edinburgh, Member States decided to strengthen some particular policies, such as research and development, external actions and financial aid to Central and Eastern European countries. Although there were several agreements on setting budgetary limits to the growth rate of expenditure, the basis of a stringent budgetary discipline was established in the Agenda 2000 agreements. These reforms have all had an impact on the level and the structure of budget expenditures, and have led to some changes in the accounting system. The budget has therefore undergone some structural reforms, the most significant being those of 1992 and 2006.

Regarding the procedure for elaboration and approval of the EU budget, there are several institutions involved. The European Commission, the Council and the Parliament participate in the process of elaborating the EU budget. However, over the past decades, the role of each institution, as well as the voting rules, have undergone

\footnotetext{
${ }^{3}$ The new members were the Czech Republic, Cyprus, Slovak Republic, Slovenia, Estonia, Hungary, Latvia, Lithuania, Malta and Poland.
} 
a number of changes (Kauppi and Widgrén, 2007). The relationship between the Council and the Parliament was controversial until the 1992 Edinburgh meeting, where an Interinstitutional Agreement between both institutions was established in order to facilitate the process of making budgetary decisions.

The budget elaboration process involves the following steps. First, based on the multi-annual financial framework in force and the budgetary guidelines for the coming year, the European Commission prepares a preliminary draft budget. Within this stage, spending priorities are established, plus caps or ceilings to limit the maximum growth rate of different budgetary sections and the total budget.

Once a preliminary draft is drawn up, the European Commission submits it to the Council and the Parliament. The budgetary authority, comprising both institutions, amends and subsequently adopts the draft budget. The Council is then expected to adopt its position on the preliminary draft budget proposed by the Commission, elaborate and approve a definitive draft budget. Next, the Parliament can modify the draft, by adopting amendments to the Council's position, or by proposing some amendments to particular expenses. The final proposed document is then approved by simple majority by the Parliament. Following this, the Council has a second reading of the document, adopting it by a larger majority than that required at the Parliament 4 A second reading by the Parliament and the definitive adoption marks the end of the process.

In this paper, we consider the voting decisions of the Council (Bindseil and Hantke, 1997; Kauppi and Widgrén, 2004). Although the Parliament has recently increased their weight in the EU decision process 5 some EU institutional features have sup-

\footnotetext{
${ }^{4}$ Usually, at least a qualified majority is required to adopt budgetary decisions at the Council.

${ }^{5}$ The Treaty of Lisbon extended the role of the Parliament. It was signed by the EU member states on 13 December 2007 and entered into force on 1 December 2009. From that moment, European Parliament could decide on both compulsory and non-compulsory expenses, extending its power and responsibilities with regard to the budget making process. With the entry into force of the Treaty of Lisbon a new system known as a "double majority" was introduced. It entered into
} 
ported the approach based on the voting framework at the Council 6

\section{Power indices: the nucleolus versus the Shapley- Shubik index}

In recent decades, there has been a growing literature, both theoretical and applied, on power measures. However, as yet, there is no consensus as to the best way to measure power. While analyzing the distribution of the EU budget among different countries, previous studies have applied the Shapley-Shubik index (SSI) (Kauppi and Widgrén, 2004), one of the mostly commonly used power measures in this context. By contrast, in this study we propose an alternative measure, the nucleolus 7 (Schmeidler, 1969). In the following, we provide strong arguments to support our choice. In the subsequent section, we compare how the two indices perform in practice, and analyze whether the conclusions reached by Kauppi and Widgrén (2004) are robust with regard to their choice of power index.

The general discussion on which power measure is best, and which properties it should possess, remains open. Napel and Widgrén (2004) therefore divide existing

force on 1 November 2014. The Nice system remained applicable during the transition period up to 31 October 2014. For an interesting discussion on the Treaty of Nice, see Heinemann (2003).

${ }^{6}$ Among others, the approval procedure applied during the period analyzed in this research (19762012) and the qualified majority required at the Council to approve the final EU budget.

${ }^{7}$ Thus, Felsenthal and Machover (1998) argue that the SSI is a measure of "P-power," where P stands for "purse," and it evaluates a voter's expected relative share of a fixed budget. As we argue in the paper (see also Le Breton et al. (2012)) the nucleolus can also be considered a power measure in the distributive setting, and can be a good alternative to the SSI. Consequently, in this paper we focus on these two measures. At the same time, the SSI can also be considered a measure of "I-power" (Felsenthal and Machover, 1998), which assesses the probability of a player casting a decisive vote. Other measures of I-power include the Banzhaf index, the Johnston index, and the Deegan-Packel index. 
studies on power indices into two "disjoint methodological camps," and propose a unified framework to link them: "On the one hand, such a framework should allow for predictions and ex post analysis of decisions based on knowledge of procedures and preferences. On the other hand, it must be open to ex ante and even completely a priori analysis of power when detailed information may either not be available or should be ignored for normative reasons." We address the discussion in a specific distributional setting, that is, the allocation of a fixed budget across the members of an organization, with the key preference assumption being that each member cares only about their own share.

Following Napel and Widgrén (2004), let us consider two requirements in turn. First, the power measure should be based on the explicit decision-making procedures and the knowledge of the preferences. To this end, it is important that the political analysis takes into account game forms. In this respect, both the SSI and the nucleolus are suitable measures to analyze bargaining situations such as the distribution of the EU budget. Each of the two measures are founded on a non-cooperative framework, in that either of them arises as a payoff from a well-specified bargaining game 8

According to the second requirement, one would not want the power analysis to be extremely sensitive to the details of the game form used to describe the noncooperative decision process. In the following, we show that only the nucleolus passes

${ }^{8}$ For instance, Gul (1989) constructs a non-cooperative game mimicking bargaining process in the markets. One of the main results state that the payoffs associated with efficient equilibria converge to the agents' Shapley values as the time between periods of the dynamic game goes to zero. Even though Gul's bargaining procedure is very natural, his results are not relevant for majority games. Some examples of a less natural bargaining procedure but more general results are Hart and Mas-Colell (1996) and Vidal-Puga (2008). As for the nucleolus, it has been proved to correspond to the vector of expected payoffs in the legislative bargaining game with random proposers according to Baron and Ferejohn (1989), where voters directly put forward proposals and vote over the division of a budget. If proposal probabilities coincide with the nucleolus, then the nucleolus is the unique vector of expected payoffs (Montero, 2006). The equality of the expected payoffs to the nucleolus also holds for other proposal probabilities depending on the voting game. 
this test.

In order to encompass the idea of a robust power measure in our specific distributional framework, we address the bargaining set, a solution concept for coalitional games (Maschler et al., 2013). The idea behind the bargaining set is that when the players decide how to divide the worth of the coalition, the player who is not satisfied with the proposed share may object to it. The objection goes against another player, calling for this player to share their part with the objecting one. The player against whom the objection is made may (or may not) have a counter objection. An objection which does not have a counter objection is called justified. The bargaining set consists of all imputations in which no player has a justified objection against any other player.

It seems that the bargaining set properly describes the decision-making procedure within EU institutions (see Section 2). Additionally, one of the properties of the bargaining set is that, contrary to the core, it is never empty. However, the bargaining set is often large, in which case there is the problem of choosing a unique outcome. In such cases, the nucleolus is a good candidate, since it always exists, it is unique and it belongs to the bargaining set. On the contrary, in general the Shapley value is not in the bargaining set. The following example supports this argument. Let us consider three individuals with individual one being a vetoer. This means that a decision is passed only when player one is present in a group voting for the decision, however if they are on their own, they cannot get the decision passed. In such a situation, the core, the nucleolus, and the bargaining set coincide, and attribute the whole surplus to player one. On the contrary, the Shapley-Shubik index is $(2 / 3,1 / 6,1 / 6)$. One may check that under the distribution according to the Shapley-Shubik index, player one has an objection. For example, player one can offer player two to share the part of player three. In this setting, player one has a lot of power, and only one extra vote is needed to validate the decision. The nucleolus models the process of Bertrand competition between players two and three. 
To summarize, both the SSI and the nucleolus have foundations in non-cooperative bargaining games, which make them suitable for ex post political analysis. However, only the nucleolus satisfies the requirement of being a measure that is open to an ex ante analysis of the distributive situations, as stated in Napel and Widgrén (2004). Given our specific framework, these arguments allow us to favour the nucleolus versus the SSI in the empirical analysis of the EU budget distribution. In the Appendix, we provide the formal definitions for the SSI and the nucleolus, as well as the figures for both power measures for the period 1958-2012.

\section{$3.1 \quad$ Example}

In this subsection we provide computations of the SSI and the nucleolus for the first EU Council of Ministers (1958 - 1972). During that period the Council consisted of representatives from six countries. The three "big" countries (Germany, Italy and France) held four votes each, the two "medium" countries (Belgium and the Netherlands) held two votes each and the "little" country (Luxembourg) held one vote. A qualified majority was set at 12 out of 17, i.e., passing a decision required at least 12 votes in favour of the decision. As has been highlighted in a number of studies 9 Luxembourg was powerless in such a situation. Since other member states held an even number of votes, Luxembourg was never formally able to make any difference in the voting process. The results are summarized in Table 1.

According to the nucleolus, a "medium" country receives half as much weight as a "big" country. This is quite intuitive, since in a minimal winning coalition, 10 a "big"

\footnotetext{
${ }^{9}$ For example, Felsenthal and Machover (1997), among others.

${ }^{10} \mathrm{~A}$ minimal winning coalition is a group of countries whereby if they all vote in favour of a decision, it is passed. Furthermore, none of the countries can be excluded, i.e., if one of the countries change the vote from "yes" to "no" the decision can no longer be passed. In this scenario, there are two types of the minimal winning coalitions: three "big" countries, or two "big" countries and two "medium" countries.
} 
Table 1: The Council of Ministers (1958 - 1972).

\begin{tabular}{llrr}
\hline \hline Country & Weight & SSI & Nucl \\
\hline Germany & 4 & 0.233 & 0.250 \\
Italy & 4 & 0.233 & 0.250 \\
France & 4 & 0.233 & 0.250 \\
Belgium & 2 & 0.150 & 0.125 \\
Netherlands & 2 & 0.150 & 0.125 \\
Luxembourg & 1 & 0 & 0 \\
\hline Quota & 12 & & \\
Total votes & 17 & & \\
Quota (\%) & 70.59 & & \\
\hline
\end{tabular}

country can be replaced by two "medium" ones. Such substitutability often holds for the nucleolus in contrast to other power indices, but it does not hold in all cases 11 As a consequence, in this case the nucleolus treats all minimal winning coalitions equally. It prescribes the total "wealth" for both types of coalitions as being equal to 0.75. In contrast, according to the SSI, the minimal winning coalitions of the first and the second type get different values, 0.766 and 0.7 respectively.

We now highlight another interesting feature of the nucleolus. In 1973, when compared to 1958, the "big" countries get the same power according to the nucleolus. However, other countries, even though they are not dummies, get zero. This is impossible for the SSI or other power indices, but it is not unusual for the nucleolus 12 As a result, the nucleolus is very different from the SSI and other indices in this example.

\footnotetext{
${ }^{11}$ For a more detailed discussion see, for example, Montero (2005).

${ }^{12}$ See, for example, Montero (2005).
} 


\section{Empirical Application}

\subsection{Data and empirical model}

As explained in the Introduction, this paper aims to identify significant key drivers and trends for EU budget allocation. In order to discuss the findings of Kauppi and Widgrén (2004), we extend their data set to include observations for the period 1976-2012. Interestingly, this period covers different phases of EU integration: from 1976 to 1980 (EU9), from 1981 to 1985 (EU10), from 1986 to 1994 (EU12), from 1995 to 2003 (EU15), from 2004 to 2006 (EU25) and from 2007 to 2012 (EU27) 13

In this respect, a general model will be proposed, where the budget share on the whole EU budget of each country depends on an index of political power and a set of variables representative of budgetary needs. The empirical model is presented as follows:

$$
b_{i t}=f\left(p_{i t}, Z_{i t}\right)+u_{i t}
$$

where $b_{i t}$ is the percentage of the total EU expenditure budget allocated to country $i$ in the year $t, p_{i t}$ is an index of political power for country $i$ and period $t$, and $Z_{i t}$ is a vector of factors representative of country $i$ 's needs in period $t$. Finally, $u_{i t}$ represents the error term.

We have proposed two alternative specifications of the dependent variable, following the procedure suggested by Kauppi and Widgrén (2004). On the one hand, we consider the total expenditure budget share that each country gets in the negotiation process $(\exp )$. On the other hand, an alternative variable is defined, introducing an adjustment to take into account the UK's budget rebate and other similar compen-

\footnotetext{
${ }^{13}$ Although data for 2013 are available, this last year was removed from the dataset. This is the first year with EU-28 with Croatia as a new EU member, so in the context of unbalanced panel data methods, this observation would need to be dropped since there is only one period for that observation (Bluhm, 2013; Wooldridge, 2010a).
} 
sations $\left(\exp _{a d j}\right) 14$

We also use some of the original variables proposed by Kauppi and Widgrén (2004) as independent variables. First, two different alternatives to measure political power discussed in the previous section are included in the analysis, 15 namely, the SSI $\left(p_{s s i}\right)$ and the nucleolus $\left(p_{\text {nucl }}\right)$. The latter power index was not originally included by Kauppi and Widgrén (2004), but has been considered for a comparison to be made with the SSI. Additionally, needs are shown using a set of variables $(Z)$ : each country's share of the total agricultural production (agri), and the ratio of each country's GDP per capita and the EU wide GDP per capita (income). Table 2 shows some descriptive statistics of the main variables.16

\footnotetext{
${ }^{14}$ This rebate was a compensatory payment made to the UK government in 1985 . The main argument in the rebate negotiations was that a high proportion of the EU budget was spent on the Common Agricultural Policy (or CAP), which benefits the UK much less than other countries, as it has a relatively small farming sector as a percentage of GDP. The compensation consists of reallocating some of the original UK monetary contributions to be paid by the remaining member states. Additionally, some minor compensation payments received by other member countries (e.g. Sweden and the Netherlands) are also included in the calculations.

${ }^{15}$ Several alternative political power indices have been considered in the estimations, such as Banzhaf, Johnston, Public Good, and Deegan-Packel indices, see Kurz (2014) for a recent overview on power indices. However, none of these power indices improved the explanatory power shown by the Shapley-Shubik or the nucleolus. The Banzhaf and the Johnston indices show similar levels of the adjusted $R^{2}$ while there are plenty of independent variables that are not significant. The Public Good and the Deegan-Packel indices seem to be more sensitive to changes in the model specification.

${ }^{16}$ Budget shares have been calculated using the information taken from the European Commission financial reports. The remaining data were taken from the Eurostat statistics website. Political power indices have been calculated as described in Appendix 1.
} 
Table 2: Summary statistics

\begin{tabular}{lcccc}
\hline \hline Variable & Mean & Std. Dev. & Min. & Max. \\
\hline exp & 0.0583 & 0.0530 & 0.0002 & 0.2256 \\
$\exp _{\text {adj }}$ & 0.0584 & 0.0529 & 0.000 & 0.2256 \\
$\mathrm{p}_{\text {ssi }}$ & 0.0643 & 0.0474 & 0.0081 & 0.1786 \\
$\mathrm{p}_{\text {nucl }}$ & 0.0643 & 0.0641 & 0.000 & 0.2500 \\
agri & 0.0643 & 0.0720 & 0.0004 & 0.3383 \\
income & 1.0000 & 0.3214 & 0.4087 & 2.6786 \\
\hline
\end{tabular}

One may observe that the SSI shows higher dispersion levels as compared to the nucleolus. The average expenditure budget percentage received is around 6\%. It is also worth mentioning that the variables representing budget needs present high levels of dispersion. Thus, country members are heterogeneous in terms of their economic structure.

\subsection{Results}

In order to carry out a sensitivity analysis, we have proposed four different specifications. Estimates appear in Tables 3-7. The four specifications are the result of combining two different dependent variables (exp in Tables 3 and 4 ; exp adj in Tables 5 and 6 ) with the two political power indices described earlier $\left(p_{s s i}\right.$ in Tables 3 and 5; $p_{\text {nucl }}$ in Tables 4 and 6). Finally, Table 7 provides the basis for a comparison of the four specifications, as marginal effects are reported.

Regarding the econometric techniques, we have considered several models. First, we keep the pooled baseline Ordinary Least Squares specification (OLS) originally proposed by Kauppi and Widgrén (2004), in order for it to be compared with more sophisticated techniques. The analysis presented in the current paper suggests unobservable heterogeneity due to the strong differences among country members from different perspectives. Moreover, since the dependent variable is a share, economet- 
ric methods should be adapted to take this into account. Thus, OLS seems to be a non-robust econometric technique in this context.

In order to resolve any issues associated with the OLS method, two fractional methodologies have been proposed. First, a Generalized Linear Model (GLM) based on a probit distribution has been applied. Second, since our panel data is clearly unbalanced, an alternative fractional model based on probit distribution has been considered (FHETPROB). Note that the nature of unbalancedness could require models that explicitly allow for heteroskedasticity (Wooldridge, 2010a, b). In both cases, a clustered option has been used to estimate the variance-covariance matrix.

Additionally, Equation (1) has been extended to include a set of variables that consider the effect of the EU enlargement $(E U)$. In this respect, a set of dummy variables has been defined: EU10, EU12, EU15, EU25, EU27. Those variables take the value of 1 when the number of country members is 10, 12, 14, 25 and 27 respectively, and 0 otherwise. Furthermore, some interactions of these dummy variables with the political power indices have been considered, since there could be different impacts of power depending on the number of countries integrated into the EU. The dummy variables have been included in OLS (denoted by $O L S_{d}$ ), GLM and FHETPROB models.

Moreover, additional dummy variables have been generated (Wooldridge, 2010b) in order to capture the panel unbalancedness structure in the context of the FHETPROB specification. Assuming that the global panel data set is composed of different subpanels $T_{i}$, both the outcome and variance equation are allowed to depend on the number of observations in each subpanel. The new dummy variables are denoted by tobs32, tobs27, tob18, tobs9, tobs6, and take the value 1 when the country is observed for $32,27,18,9$ and 6 years respectively, and 0 otherwise.

The results show some general facts that are observed in the majority of cases. Both power and needs are significant key drivers of budget allocation. Thus, the higher the political power, the higher the expenditure share. Additionally, those 
countries with more intensive agricultural activity and lower relative income emerge as the beneficiaries of EU policies, as they receive higher shares of the overall budget.

Regarding the econometric models, and comparing both fractional techniques, it seems that FHETPROB enables an encreased significance of the three main variables related to power and needs. The inclusion of a variance equation based on the unbalancedness structure helps to refine the results. In all the specifications, the majority of variables explaining the variance are highly significant.

When comparing the performance of different models and when focusing on alternative power indices, there are also interesting findings. In terms of OLS regressions, the adjusted $R^{2}$ values show that models based on $p_{s s i}$ have a higher explanatory power than those based on $p_{\text {nucl }}$. However, the differences are considerably smaller when dummy variables representative of EU enlargement process are included in the analysis. Thus, both power indices seem to perform similarly. Differences in terms of information criteria (aic, bic) show that fractional models using different power indices are also very close to each other. Comparing Tables 5 and 6 , the highest lag in information criteria between both power indices is registered for the specification where adjusted budget shares are explained and heteroskedascitity is modelled. In this particular case, the nucleolus performs better.

Regarding enlargement, two interesting effects are noted. First, the EU dummy variables show that budget shares decrease with the EU size. Thus, the larger the number of country members, the lower the average budget share. Second, power interactions with temporal dummies show that there are different impacts of power in different subperiods, especially when the nucleolus is included in the specifications. In general, the period 2004-2006 (EU25) is one where country members achieve higher relative returns from their political power. When the number of country members experience a substantial increase, those countries with higher power levels obtain higher relative gains.

As mentioned earlier, Table 7 provides marginal effects, allowing the compari- 
Table 3: Total budget shares $(\exp )$ and the SSI $\left(p_{s s i}\right)$

\begin{tabular}{|c|c|c|c|c|}
\hline & (1) & $(2)$ & $(3)$ & (4) \\
\hline & OLS & $\mathrm{OLS}_{\mathrm{d}}$ & GLM & FHETPROB \\
\hline p_ssi & $0.545^{* *}$ & $0.493^{* *}$ & $3.781^{* *}$ & $3.675^{* *}$ \\
\hline agri & $0.352^{* *}$ & $0.337^{* *}$ & $1.682^{* *}$ & $1.768^{* *}$ \\
\hline income & $-0.005^{*}$ & $-0.004^{+}$ & $-0.157^{+}$ & $-0.263^{* *}$ \\
\hline p_ssiEU10 & & 0.034 & 0.490 & 0.659 \\
\hline p_ssiEU12 & & 0.001 & 1.305 & 1.401 \\
\hline p_ssiEU15 & & $0.199^{* *}$ & $3.213^{*}$ & 1.787 \\
\hline p_ssiEU25 & & $0.248^{* *}$ & $7.293^{* *}$ & 2.902 \\
\hline p_ssiEU27 & & $0.150^{*}$ & $7.128^{* *}$ & 2.096 \\
\hline EU10 & & -0.006 & -0.075 & -0.103 \\
\hline EU12 & & -0.002 & -0.098 & -0.143 \\
\hline EU15 & & $-0.014^{*}$ & -0.233 & -0.103 \\
\hline EU25 & & $-0.014^{*}$ & $-0.482^{*}$ & -0.142 \\
\hline EU27 & & $-0.010^{+}$ & $-0.450^{*}$ & -0.034 \\
\hline tobs32 & & & & -0.569 \\
\hline tobs 27 & & & & $0.540^{* *}$ \\
\hline tobs18 & & & & $-4.400^{* *}$ \\
\hline tobs9 & & & & $0.665^{* *}$ \\
\hline tobs6 & & & & $0.918^{* *}$ \\
\hline _cons & $0.006^{*}$ & $0.012^{+}$ & $-1.830^{* *}$ & $-1.722^{* *}$ \\
\hline \multicolumn{5}{|l|}{$\operatorname{lnsigma2}$} \\
\hline tobs32 & & & & 0.370 \\
\hline tobs 27 & & & & $-0.419^{* *}$ \\
\hline tobs18 & & & & $1.053^{* *}$ \\
\hline tobs 9 & & & & $-0.711^{* *}$ \\
\hline tobs6 & & & & $-1.112^{* *}$ \\
\hline cluster & no & no & yes & yes \\
\hline$N$ & 575 & 575 & 575 & 575 \\
\hline$R^{2} \_a d j$ & 0.88 & 0.88 & & \\
\hline chi2 & & & 580.92 & \\
\hline aic & -2940.72 & -2945.21 & 200.09 & 269.57 \\
\hline bic & -2923.30 & -2884.25 & 261.05 & 356.66 \\
\hline
\end{tabular}

${ }^{t} p<0.10, * 000.05,{ }^{*}{ }^{*}<0.01$ 
Table 4: Total budget shares (exp) and nucleolus $\left(p_{\text {nucl }}\right)$

\begin{tabular}{|c|c|c|c|c|}
\hline & (1) & $(2)$ & (3) & (4) \\
\hline & OLS & $\mathrm{OLS}_{d}$ & GLM & FHETPROB \\
\hline p_nucl & $0.221^{* *}$ & $0.204^{* *}$ & $1.369^{*}$ & $1.345^{*}$ \\
\hline agri & $0.504^{* *}$ & $0.370^{* *}$ & $1.931^{* *}$ & $1.981^{* *}$ \\
\hline income & $-0.010^{* *}$ & $-0.005^{*}$ & $-0.168^{+}$ & $-0.277^{* *}$ \\
\hline p_nuclEU10 & & 0.037 & $0.471^{+}$ & $0.592^{*}$ \\
\hline p_nuclEU12 & & $0.199^{* *}$ & $3.041^{* *}$ & $3.233^{* *}$ \\
\hline p_nuclEU15 & & $0.463^{* *}$ & $5.574^{* *}$ & $3.966^{* *}$ \\
\hline p_nuclEU25 & & $0.528^{* *}$ & $10.102^{* *}$ & $5.008^{*}$ \\
\hline p_nuclEU27 & & $0.419^{* *}$ & $9.813^{* *}$ & $4.141^{*}$ \\
\hline EU10 & & $-0.009^{+}$ & $-0.108^{*}$ & $-0.134^{* *}$ \\
\hline EU12 & & $-0.026^{* *}$ & $-0.323^{* *}$ & $-0.374^{* *}$ \\
\hline EU15 & & $-0.043^{* *}$ & $-0.507^{* *}$ & $-0.364^{*}$ \\
\hline EU25 & & $-0.043^{* *}$ & $-0.770^{* *}$ & $-0.388^{+}$ \\
\hline EU27 & & $-0.039^{* *}$ & $-0.731^{* *}$ & -0.280 \\
\hline tobs32 & & & & -0.014 \\
\hline tobs 27 & & & & $0.599^{* *}$ \\
\hline tobs18 & & & & $-3.451^{* *}$ \\
\hline tobs 9 & & & & $0.705^{* *}$ \\
\hline tobs6 & & & & $0.889^{* *}$ \\
\hline _cons & $0.022^{* *}$ & $0.041^{* *}$ & $-1.561^{* *}$ & $-1.454^{* *}$ \\
\hline \multicolumn{5}{|l|}{ lnsigma2 } \\
\hline tobs32 & & & & 0.083 \\
\hline tobs 27 & & & & $-0.483^{* *}$ \\
\hline tobs18 & & & & $0.889^{* *}$ \\
\hline tobs 9 & & & & $-0.757^{* *}$ \\
\hline tobs6 & & & & $-1.095^{* *}$ \\
\hline cluster & no & no & yes & yes \\
\hline$N$ & 575 & 575 & 575 & 575 \\
\hline $\mathrm{R}^{2} \_$adj & 0.84 & 0.87 & & \\
\hline chi2 & & & 641.14 & \\
\hline aic & -2808.05 & -2912.11 & 200.30 & 269.76 \\
\hline bic & -2790.63 & -2851.15 & 261.26 & 356.85 \\
\hline
\end{tabular}

${ }^{+} p<0.10, \vec{p}<0.05,{ }^{*}{ }_{p}<0.01$ 
Table 5: Adjusted budget shares $\left(e x p_{a d j}\right)$ and the SSI $\left(p_{s s i}\right)$

\begin{tabular}{|c|c|c|c|c|}
\hline & (1) & $(2)$ & (3) & (4) \\
\hline & OLS & $\mathrm{OLS}_{\mathrm{d}}$ & GLM & FHETPROB \\
\hline p_ssi & $0.768^{* *}$ & $0.733^{* *}$ & $5.148^{* *}$ & $5.143^{* *}$ \\
\hline agri & $0.200^{* *}$ & $0.157^{* *}$ & $0.704^{*}$ & $0.718^{*}$ \\
\hline income & -0.002 & 0.001 & -0.103 & $-0.223^{*}$ \\
\hline p_ssiEU10 & & 0.034 & 0.456 & 0.493 \\
\hline p_ssiEU12 & & 0.080 & $1.876^{*}$ & $2.058^{*}$ \\
\hline p_ssiEU15 & & $0.326^{* *}$ & $4.070^{* *}$ & 2.735 \\
\hline p_ssiEU25 & & $0.316^{* *}$ & $7.913^{* *}$ & $4.256^{+}$ \\
\hline p_ssiEU27 & & $0.210^{* *}$ & $7.571^{* *}$ & 3.132 \\
\hline EU10 & & -0.005 & -0.068 & -0.071 \\
\hline EU12 & & -0.007 & -0.141 & -0.192 \\
\hline EU15 & & $-0.020^{* *}$ & -0.281 & -0.153 \\
\hline EU25 & & $-0.012^{+}$ & $-0.490^{*}$ & -0.188 \\
\hline EU27 & & -0.008 & $-0.443^{*}$ & -0.060 \\
\hline tobs32 & & & & -4.990 \\
\hline tobs27 & & & & $0.490^{* *}$ \\
\hline tobs18 & & & & $-5.168^{* *}$ \\
\hline tobs9 & & & & $0.414^{* *}$ \\
\hline tobs6 & & & & $0.931^{* *}$ \\
\hline _cons & -0.002 & 0.000 & $-1.926^{* *}$ & $-1.808^{* *}$ \\
\hline \multicolumn{5}{|l|}{$\operatorname{lnsigma2}$} \\
\hline tobs32 & & & & 1.454 \\
\hline tobs27 & & & & $-0.376^{* *}$ \\
\hline tobs18 & & & & $1.163^{* *}$ \\
\hline tobs 9 & & & & $-0.491^{* *}$ \\
\hline tobs6 & & & & $-1.091^{* *}$ \\
\hline cluster & no & no & yes & yes \\
\hline$N$ & 575 & 575 & 575 & 575 \\
\hline$R^{2}$ _adj & 0.87 & 0.88 & & \\
\hline chi2 & & & 1121.58 & \\
\hline aic & -2926.94 & -2964.45 & 199.72 & 271.41 \\
\hline bic & -2909.53 & -2903.49 & 260.68 & 362.85 \\
\hline
\end{tabular}

${ }^{t} p<0.10, \stackrel{*}{p}<0.05,{ }^{*} \stackrel{*}{p}<0.01$ 
Table 6: Adjusted budget shares $\left(e x p_{a d j}\right)$ and nucleolus $\left(p_{\text {nucl }}\right)$

\begin{tabular}{|c|c|c|c|c|}
\hline & (1) & (2) & (3) & (4) \\
\hline & OLS & $\mathrm{OLS}_{\mathrm{d}}$ & GLM & FHETPROB \\
\hline p_nucl & $0.324^{* *}$ & $0.318^{* *}$ & $2.015^{* *}$ & $2.018^{* *}$ \\
\hline agri & $0.404^{* *}$ & $0.198^{* *}$ & $0.965^{*}$ & $0.974^{*}$ \\
\hline income & $-0.009^{* *}$ & -0.001 & -0.114 & $-0.251^{* *}$ \\
\hline p_nuclEU10 & & 0.039 & $0.477^{+}$ & $0.602^{*}$ \\
\hline p_nuclEU12 & & $0.362^{* *}$ & $4.206^{* *}$ & $4.463^{* *}$ \\
\hline p_nuclEU15 & & $0.719^{* *}$ & $7.274^{* *}$ & $5.688^{* *}$ \\
\hline p_nuclEU25 & & $0.726^{* *}$ & $11.574^{* *}$ & $7.024^{* *}$ \\
\hline p_nuclEU27 & & $0.604^{* *}$ & $11.070^{* *}$ & $5.840^{* *}$ \\
\hline EU10 & & $-0.010^{+}$ & $-0.114^{*}$ & $-0.141^{* *}$ \\
\hline EU12 & & $-0.041^{* *}$ & $-0.439^{* *}$ & $-0.493^{* *}$ \\
\hline EU15 & & $-0.062^{* *}$ & $-0.646^{* *}$ & $-0.499^{*}$ \\
\hline EU25 & & $-0.055^{* *}$ & $-0.866^{* *}$ & $-0.505^{*}$ \\
\hline EU27 & & $-0.050^{* *}$ & $-0.810^{* *}$ & $-0.379^{+}$ \\
\hline tobs32 & & & & -0.217 \\
\hline tobs27 & & & & $0.589^{* *}$ \\
\hline tobs18 & & & & $-3.597^{* *}$ \\
\hline tobs9 & & & & $0.464^{* *}$ \\
\hline tobs6 & & & & $0.890^{* *}$ \\
\hline _cons & $0.020^{* *}$ & $0.043^{* *}$ & $-1.574^{* *}$ & $-1.439^{* *}$ \\
\hline \multicolumn{5}{|l|}{$\operatorname{lnsigma2}$} \\
\hline tobs32 & & & & 0.193 \\
\hline tobs27 & & & & $-0.487^{* *}$ \\
\hline tobs18 & & & & $0.909^{* *}$ \\
\hline tobs9 & & & & $-0.547^{* *}$ \\
\hline tobs6 & & & & $-1.083^{* *}$ \\
\hline cluster & no & no & yes & yes \\
\hline$N$ & 575 & 575 & 575 & 575 \\
\hline $\mathrm{R}^{2}$ _adj & 0.81 & 0.87 & & \\
\hline chi2 & & & 1283.98 & \\
\hline aic & -2704.59 & -2906.01 & 200.04 & 269.71 \\
\hline bic & -2687.18 & -2845.05 & 261.00 & 356.80 \\
\hline
\end{tabular}

${ }^{+} p<0.10, * 0.05,{ }^{*}{ }_{p}^{*}<0.01$ 
sion of all models and specifications in terms of impact of power and needs. OLS techniques tend to overestimate the value of the coefficients, while fractional models smooth the estimates, since they are more appropriate when modelling shares. Another interesting idea emerges where power indices have a higher impact on adjusted budget share specifications. According to our expectations, once the budget shares are adjusted to take the UK rebate and other compensation payments into consideration, the explanatory weight of power increases. Nevertheless, the relative weight of political power is lower when considering the nucleolus, while needs' factors become more important. There is no doubt that political power matters, but not as much as the models with the SSI as a power index have shown. Thus, the specifications based on the nucleolus show a more balanced situation between power and needs. The result reinforces the idea that the impact of political power on budget share is not as important as Kauppi and Widgrén (2004) predicted 17

\footnotetext{
${ }^{17}$ In this respect, the original estimates of the SSI by Kauppi and Widgrén (2004) for the period 1976-2001 (considering annual data) ranged between 0.545 and 0.645 and between 0.783 and 0.858 for the total budget shares and adjusted budget shares respectively. The impact of agriculture was estimated in a range between 0.387 and 0.405 and between 0.252 and 0.236 for the total budget shares and adjusted budget shares respectively. Finally, estimated income coefficient registered values between -0.025 and 0.008 and between -0.022 and 0.003 for the total budget shares and adjusted budget shares respectively.
} 
Table 7: Power versus needs: marginal effects

\begin{tabular}{|c|c|c|c|c|}
\hline & OLS & $\mathrm{OLS}_{\mathrm{d}}$ & GLM & FHETPROB \\
\hline \multicolumn{5}{|c|}{ Total budget share/SSI } \\
\hline p_ssi & $0.545^{* *}$ & $0.493^{* *}$ & $0.345^{* *}$ & $0.426^{* *}$ \\
\hline agri & $0.352^{* *}$ & $0.337^{* *}$ & $0.153^{* *}$ & $0.205^{* *}$ \\
\hline income & $-0.005^{*}$ & $-0.004^{+}$ & $-0.014^{+}$ & $-0.031^{* *}$ \\
\hline \multicolumn{5}{|c|}{ Total budget share/nucleolus } \\
\hline p_nucl & $0.221^{* *}$ & $0.204^{* *}$ & $0.125^{*}$ & $0.161^{*}$ \\
\hline agri & $0.504^{* *}$ & $0.370^{* *}$ & $0.176^{* *}$ & $0.237^{* *}$ \\
\hline income & $-0.010^{* *}$ & $-0.005^{*}$ & $-0.014^{+}$ & $-0.033^{* *}$ \\
\hline \multicolumn{5}{|c|}{ Adjusted budget share/SSI } \\
\hline p_ssi & $0.768^{* *}$ & $0.733^{* *}$ & $0.466^{* *}$ & $0.563^{* *}$ \\
\hline agri & $0.200^{* *}$ & $0.157^{* *}$ & $0.064^{*}$ & $0.079^{*}$ \\
\hline income & -0.002 & 0.001 & -0.009 & $-0.024^{*}$ \\
\hline \multicolumn{5}{|c|}{ Adjusted budget share/nucleolus } \\
\hline p_nucl & $0.324^{* *}$ & $0.318^{* *}$ & $0.183^{* *}$ & $0.235^{* *}$ \\
\hline agri & $0.404^{* *}$ & $0.198^{* *}$ & $0.088^{*}$ & $0.114^{*}$ \\
\hline income & $-0.009^{* *}$ & -0.001 & -0.010 & $-0.029^{* *}$ \\
\hline
\end{tabular}

\section{Discussion and future research}

The main contribution of this paper is to highlight the role of political power on the EU budget decisions. Various key drivers of budget shares allocated to each EU member country have been identified. Both power and needs are significant factors in explaining expenditure budget allocation among EU member states. Some previous empirical analysis (Kauppi and Widgrén, 2004, 2007) show strong prevalence of political power motives. Their results indicate that a large percentage of budget expenditures can be attributed to selfish power politics, leaving a small contribution to the so-called benevolent EU need-based budget policies.

We have carried out an empirical analysis to revisit the findings of Kauppi and Widgrén (2004). To this end, we have updated their data set (originally from 1976 to 2001, 
the range has been extended to 2012). Additionally we have compared alternative political power measures and have applied more sophisticated and rigorous econometric techniques. We have argued that the nucleolus (Schmeidler, 1969) is a good alternative to the SSI when explaining the budget share of EU member states, from both a theoretical and an empirical perspective.

Our findings show that under simple econometric specifications, both power indices behave in a similar way, although the SSI is slightly superior in terms of explanatory power. However, when using more sophisticated and adequate econometric techniques, the nucleolus seems to perform better than the SSI 18 In particular, the nucleolus performs better when considering adjusted budget shares (by compensations, such as the UK rebate), and when we adjust for the unbalancedness of the panel data. Moreover, the higher the number of countries competing for EU budget, the higher the impact of political power on budget shares.

Additionally, we find that the relative weight of political power based on the nucleolus when explaining budget shares is lower than predictions of other models. A partial explanation may be the fact that the nucleolus can assign zero power to non dummy players, which is not the case for the Shapley-Shubik and the Banzhaf indices. Indeed, this occurs for all voting systems until 1994 (see Appendix 1). Needs also matter, and countries with lower relative income levels and a broader irrigation sector are recipients of a significant amount of EU resources. These findings are consistent with the idea that the EU budget is allocated to develop key policies such as the common agricultural policy and the structural funds. Although political power has an impact on the EU budgetary decisions, this impact seems to be more moderate than estimated in previous literature. Definitively, the solidarity principle emerges as

\footnotetext{
${ }^{18}$ In general, the voting power need not be proportional to the voting weights (Felsenthal and Machover, 1998). However, following a naïve approach, we have also performed estimations using the voting weights instead of the power indices. The results imply that the specifications based on the power indices perform better. More details are available from the authors upon request.
} 
a significant key driver of the EU budgetary allocation.

Finally, we would like to pursue this line of research further through a more focused analysis of specific sections of the EU budget. When modelling bargaining schemes, interactions among different sections of the EU budget will be considered. Additionally, further empirical analysis will aim to detect factors that increase the probability of receiving higher budget shares for specific policies.

\section{Acknowledgements}

We are grateful to professor Heikki Kauppi, who shared the original data set (19762001) with us. We would also like to thank Michel Le Breton, María Montero, François Salanié and Roberto Martínez Espiñeira for their input during insightful discussions at the early stages of our work, and the Editor and two anonymous referees for their comments and suggestions.

\section{References}

Aksoy D (2010). Who gets what, when, and how revisited: Voting and proposal powers in the allocation of the EU budget, European Union Politics 11(2), 171194.

Anderson K and Tyers R (1995). Implications of EC expansion for European agricultural policies, trade and welfare, in R Baldwin, ed., Expanding the Membership of the European Union, Cambridge University Press.

Baron D and Ferejohn J (1989). Bargaining in legislatures, American Political Science Review 83, 1181-1206.

Bindseil U and Hantke C (1997). The power distribution in decision making among EU member states, European Journal of Political Economy 13(1), 171 - 185. 
Bluhm R (2013). fhetprob: A fast QMLE Stata routine for fractional probit models with multiplicative heteroskedasticity, Technical report.

Courchene T et al. (1993). Stable money-sounds finances: Community public finance in the perspective of EMU, European Economy 53.

Felsenthal D and Machover M (1997). The Weighted Voting Rule in the EU's Council of Ministers, 1958-95: Intentions and Outcome, Electoral Studies 16(1), 33-47.

Felsenthal D and Machover M (1998). The Measurement of Voting Power. Theory and Practice, Problems and Paradoxes, Edward Elgar, Cheltenham.

Gul F (1989). Bargaining Foundations of Shapley Value, American Journal of Political Science 1(57), 81-95.

Hart S and Mas-Colell A (1996). Bargaining and Value, Econometrica 64(2), 357-380.

Heinemann F (2003). The political economy of EU enlargement and the Treaty of Nice, European Journal of Political Economy 19(1), 17 - 31.

Kandogan Y (2000). Political economy of eastern enlargement of the European Union: Budgetary costs and reforms in voting rules, European Journal of Political Economy 16(4), $685-705$.

Kauppi H and Widgrén M (2004). What determines EU decision making? Needs, power or both?, Economic Policy 19(39), 221-266.

Kauppi H and Widgrén M (2007). Voting rules and budget allocation in the enlarged EU, European Journal of Political Economy 23(3), 693-706.

Kurz S (2014). The inverse problem for power distributions in committees, p. 46. arXiv preprint http://arxiv.org/abs/1402.0988, submitted. 
Le Breton M, Montero M and Zaporozhets V (2012). Voting Power in the EU Council of Ministers and Fair Decision Making in Distributive Politics, Mathematical Social Sciences 63, 159-173.

Maschler M, Peleg B and Shapley L (1979). Geometric properties of the kernel, nucleolus, and related solution concepts, Mathematics of Operations Research 4(4), 303338.

Maschler M, Solan E and Zamir S (2013). Game Theory, Cambridge University Press.

Montero M (2005). On the Nucleolus as a Power Index, Homo Oeconomicus XXII(4), 551-567.

Montero M (2006). Noncooperative bargaining foundations of the nucleolus in majority games, Games and Economic Behavior 54, 380-397.

Montero M (2013). On the Nucleolus as a Power Index in Power, Voting and Voting Power: 30 Years After, edited by M. Holler and H. Nurmi, Springer, pp. 283-299.

Napel S and Widgrén M (2004). Power measurement as sensitivity analysis, Journal of Theoretical Politics 16, 517-538.

Schmeidler D (1969). The nucleolus of a characteristic function game, SIAM Journal on Applied Mathematics 17, 1163-1170.

Shapley L and Shubik M (1954). A method for evaluating the distribution of power in a committee system, American Political Science Review 48, 787-792.

Tangermann S (1997). Reforming the CAP: A prerequisite for eastern enlargement, in H Siebert, ed., Quo Vadis Europe?, Springer, pp. 151-179.

Vidal-Puga J J (2008). Forming coalitions and the Shapley NTU value, European Journal of Operational Research 190(3), 659-671. 
Wooldridge J (2010a). Correlated Random Effects Models with Unbalanced Panels, Technical report, Michigan State University.

Wooldridge J (2010b). Econometric Analysis of Cross Section and Panel Data, MIT Press. 
Appendix 1: The SSI and the nucleolus in the Council of Ministers 1958-2002

\begin{tabular}{|c|c|c|c|c|c|c|c|c|c|c|}
\hline \multirow[t]{2}{*}{ Country } & \multicolumn{2}{|c|}{$1958-1972$} & \multicolumn{2}{|c|}{$1973-1980$} & \multicolumn{2}{|c|}{$1981-1985$} & \multicolumn{2}{|c|}{$1986-1994$} & \multicolumn{2}{|c|}{$1995-2002$} \\
\hline & SSI & Nucl & SSI & Nucl & SSI & Nucl & SSI & Nucl & SSI & Nucl \\
\hline France & 0.233 & 0.250 & 0.179 & 0.250 & 0.174 & 0.250 & 0.134 & 0.138 & 0.117 & 0.115 \\
\hline Germany & 0.233 & 0.250 & 0.179 & 0.250 & 0.174 & 0.250 & 0.134 & 0.138 & 0.117 & 0.115 \\
\hline Italy & 0.233 & 0.250 & 0.179 & 0.250 & 0.174 & 0.250 & 0.134 & 0.138 & 0.117 & 0.115 \\
\hline United Kingdom & - & - & 0.179 & 0.250 & 0.174 & 0.250 & 0.134 & 0.138 & 0.117 & 0.115 \\
\hline Belgium & 0.150 & 0.125 & 0.081 & 0 & 0.071 & 0 & 0.064 & 0.069 & 0.056 & 0.057 \\
\hline Netherlands & 0.150 & 0.125 & 0.081 & 0 & 0.071 & 0 & 0.064 & 0.069 & 0.056 & 0.057 \\
\hline Luxembourg & 0 & 0 & 0.001 & 0 & 0.030 & 0 & 0.012 & 0 & 0.021 & 0.023 \\
\hline Denmark & - & - & 0.057 & 0 & 0.030 & 0 & 0.043 & 0.034 & 0.035 & 0.034 \\
\hline Ireland & - & - & 0.057 & 0 & 0.030 & 0 & 0.043 & 0.034 & 0.035 & 0.034 \\
\hline Greece & - & - & - & - & 0.071 & 0 & 0.064 & 0.069 & 0.056 & 0.057 \\
\hline Spain & - & - & - & - & - & - & 0.111 & 0.103 & 0.095 & 0.092 \\
\hline Portugal & - & - & - & - & - & - & 0.064 & 0.069 & 0.056 & 0.057 \\
\hline Austria & - & - & - & - & - & - & - & - & 0.045 & 0.046 \\
\hline Sweden & - & - & - & - & - & - & - & - & 0.045 & 0.046 \\
\hline Finland & - & - & - & - & - & - & - & - & 0.035 & 0.034 \\
\hline
\end{tabular}

Source: Adapted from Le Breton et al. (2012). 
Appendix 1 (cont.): The SSI and the nucleolus in the Council of Ministers under the Treaty of Nice,

2003-2012

\begin{tabular}{|c|c|c|c|c|c|c|}
\hline \multirow[t]{2}{*}{ Country } & \multicolumn{2}{|c|}{2003} & \multicolumn{2}{|c|}{$2004-2006$} & \multicolumn{2}{|c|}{$2007-2012$} \\
\hline & SSI & Nucl & SSI & Nucl & SSI & Nucl \\
\hline France & 0.129 & 0.122 & 0.094 & 0.090 & 0.087 & 0.084 \\
\hline Germany & 0.137 & 0.122 & 0.095 & 0.090 & 0.088 & 0.084 \\
\hline Italy & 0.128 & 0.122 & 0.094 & 0.090 & 0.087 & 0.084 \\
\hline United Kingdom & 0.129 & 0.122 & 0.094 & 0.090 & 0.087 & 0.084 \\
\hline Belgium & 0.046 & 0.051 & 0.036 & 0.037 & 0.034 & 0.035 \\
\hline Netherlands & 0.052 & 0.051 & 0.039 & 0.040 & 0.037 & 0.038 \\
\hline Denmark & 0.028 & 0.031 & 0.021 & 0.022 & 0.019 & 0.020 \\
\hline Ireland & 0.028 & 0.031 & 0.021 & 0.022 & 0.019 & 0.020 \\
\hline Luxembourg & 0.016 & 0.020 & 0.012 & 0.012 & 0.011 & 0.012 \\
\hline Greece & 0.046 & 0.051 & 0.036 & 0.037 & 0.034 & 0.035 \\
\hline Portugal & 0.046 & 0.051 & 0.036 & 0.037 & 0.034 & 0.035 \\
\hline Spain & 0.110 & 0.112 & 0.087 & 0.084 & 0.080 & 0.078 \\
\hline Austria & 0.038 & 0.041 & 0.030 & 0.031 & 0.028 & 0.029 \\
\hline Finland & 0.028 & 0.031 & 0.021 & 0.022 & 0.019 & 0.020 \\
\hline Sweden & 0.038 & 0.041 & 0.030 & 0.031 & 0.028 & 0.029 \\
\hline Cyprus & - & - & 0.012 & 0.012 & 0.011 & 0.012 \\
\hline Slovakia & - & - & 0.021 & 0.022 & 0.019 & 0.020 \\
\hline Slovenia & - & - & 0.012 & 0.012 & 0.011 & 0.012 \\
\hline Estonia & - & - & 0.012 & 0.012 & 0.011 & 0.012 \\
\hline Hungary & - & - & 0.036 & 0.037 & 0.034 & 0.035 \\
\hline Latvia & - & - & 0.012 & 0.012 & 0.011 & 0.012 \\
\hline Lithuania & - & - & 0.021 & 0.022 & 0.019 & 0.020 \\
\hline Malta & - & - & 0.009 & 0.009 & 0.008 & 0.009 \\
\hline Poland & - & - & 0.087 & 0.084 & 0.080 & 0.078 \\
\hline Czech Republic & - & - & 0.036 & 0.037 & 0.034 & 0.035 \\
\hline Bulgaria & - & - & - & - & 0.028 & 0.029 \\
\hline Romania & - & - & 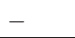 & - & 0.040 & 0.041 \\
\hline
\end{tabular}

Source: Own elaboration. 


\section{Appendix 2}

\subsection{Technical preliminaries}

In this section, we introduce basic notions commonly used to model voting situations, and then briefly discuss the nucleolus and the Shapley-Shubik index.

We consider a set $N=\{1, \ldots, n\}$ of $n$ players or voters, which is often referred to as an assembly. The power set $2^{N}$ contains all the subsets of $N$. A non-empty subset $S \subseteq N$ is called a coalition. The coalition $N$ is said to be the grand coalition.

A cooperative game with transferable utility in characteristic function form, is a pair $(N, v)$ with $N$ the set of players and:

$$
v: 2^{N} \longrightarrow \mathbb{R}: S \longmapsto v(S)
$$

which is a map that satisfies $v(\emptyset)=0$. The map $v$ is called the characteristic function. The value $v(S)$ is said to be the value or the worth of coalition $S$. For simplicity, we refer to these games as "games in TU form."

The game $(N, v)$ is said to be simple if:

- the value of a coalition is either 0 or $1: v(S) \in\{0,1\}$ for all $S \subseteq N$,

- the value of grand coalition is $1: v(N)=1$.

A coalition with a value equal to 1 is said to be winning, and a coalition with a value equal to 0 is said to be losing. A winning coalition $S$ is minimal if it does not contain any other winning coalition: $v(S)=1$ and $v(T)=0$ for all $T \subset S$. Furthermore, the set of winning coalitions is denoted by $\mathcal{W}$ and the set of minimal winning coalitions is denoted by $\mathcal{W}^{m}$. The simple game $(N, v)$ is fully determined through the pair $(N, \mathcal{W})$.

Furthermore, the simple game is said to be monotonic if supersets of winning coalitions are winning, i.e., if $S \in \mathcal{W}$ and $T \supset S$, then $T \in \mathcal{W}$. A monotonic simple game is also called a simple voting game 19

\footnotetext{
${ }^{19}$ Several authors also use the term simple game for simple voting games, i.e., where monotonicity
} 
Voting situations are often described by weighted majority games, for example the one in the EU Council of Ministers. The game $(N, v)$ is said to be a weighted majority game if there is an $n$-tuple $w=\left(\omega_{1}, \ldots, \omega_{n}\right)$ of non-negative weights with $\omega_{1}+\omega_{2}+\ldots+\omega_{n}=1$ and a non-negative quota $q$ such that $v(S)=1$, if and only if, the total weight of the players in $S$ exceeds the quota $q$, i.e.,

$$
v(S)=1 \text {, if and only if, } \sum_{i \in S} \omega_{i} \geq q
$$

The pair $[q ; \omega]$ is called a representation of the game $(N, v)$. Typical examples of weighted majority games are:

- the majority game: $w=(\underbrace{1,1, \ldots, 1}_{n})$ and $q=(n+1) / 2$,

- the unanimity game: $w=(1,1, \ldots, 1)$ and $q=n$,

- the dictator game: $w=(1,0,0, \ldots, 0)$ and $q=1$ (player 1 is the dictator).

A measure of power is a map $\xi$ from the set of simple voting games $(N, v)$ to the set of $n$-tuples of real numbers. The value $\xi_{i}=\xi_{i}(N, v)$ is the power of player $i$ in the game $(N, v)$, and it satisfies $0 \leq \xi_{i} \leq 1$.

\subsection{Shapley-Shubik Index}

One of the most famous power measures used in the literature is the Shapley-Shubik index 20 Several approaches are used in the literature to present and interpret the Shapley-Shubik index. Shapley and Shubik (1954) apply the following scheme to introduce their index. The players vote in order and as a majority is reached, the bill is passed. The critica 21 voter is assumed to be given credit for having passed the bill.

is assumed.

${ }^{20}$ For the definitions and properties, see Felsenthal and Machover (1998).

${ }^{21}$ Player $i$ in coalition $S$ is said to be critical in $S$ if without player $i$ the coalition left behind is loosing, i.e.,

$$
i \text { is critical in } S \quad \text { if } \quad i \in S \in \mathcal{W} \text { and } S \backslash\{i\} \notin \mathcal{W} .
$$

If $i$ is not critical in any $S \in \mathcal{W}$, then $i$ is a dummy. 
The index is then determined through the assumption of a random voting order.

Definition 1 Let $(N, v)$ be a simple voting game. The Shapley-Shubik index (SSI) of player $i$ is defined by:

$$
\phi_{i}=\phi_{i}(N, v)=\sum_{S: i \text { is critical in } S} \frac{(|S|-1) !(n-|S|) !}{n !} \text { for all } i \in N .
$$

The advantage of this approach is that it is simple and non-technical. However, the authors emphasize that this scheme, "is just a convenient conceptual device." The main shortcoming of this scheme is that this voting model cannot be considered realistic: there is no reason why the pivot voter should get all the credit, or why the order of the grand coalition formation should matter 22 With respect to the computation the Shapley-Shubik indices of our EU instances, we remark that looping over all $2^{n}$ coalitions and determining the critical voters was quick enough for our purpose, i.e., more advanced methods involving generating functions were not needed.

\subsection{The Nucleolus}

The nucleolus is a solution concept for cooperative games, which was first formulated by Schmeidler (1969). In order to introduce it let us consider a characteristic function game $(N, v)$. For convenience, for some vector $x$ we define:

$$
x(S) \equiv \sum_{i \in S} x_{i} \text { for any } S \subseteq N .
$$

A payoff vector $x=\left(x_{1}, \ldots, x_{n}\right)$ with $x_{i} \geq v(i)$ and $x(N)=v(N)$ is called an imputation. We denote by $X(N, v)$ the set of all imputations of the game $(N, v)$.

Let $x$ be an imputation, then for any coalition $S$ the excess of $S$ is defined as:

$$
e(S, x)=v(S)-x(S)
$$

One might interpret this number as a measure of "dissatisfaction" for coalition $S$ at imputation $x$. For any imputation $x$ let $S_{1}, \ldots, S_{2^{n}-1}$ be an ordering of the

\footnotetext{
${ }^{22}$ For more detailed discussion, see Felsenthal and Machover (1998).
} 
coalitions for which $e\left(S_{l}, x\right) \geq e\left(S_{l+1}, x\right)$ for $l=1, \ldots, 2^{n}-2$. Let $E(x)$ be the vector of excess defined as $E_{l}(x)=e\left(S_{l}, x\right)$ for all $l=1, \ldots, 2^{n}-1$. We say that $E(x)$ is lexicographically less than $E(y)$ if:

$$
E_{l}(x)<E_{l}(y) \text { for the smallest } l \text { for which } E_{l}(x) \neq E_{l}(y)
$$

We denote this relation by $E(x) \prec_{\text {lex } \min } E(y)$.

Definition 2 The nucleolus is the set of imputations $x$ for which the vector $E(x)$ is lexicographically minimal:

$$
\nu=\nu(N, v)=\left\{x \in X(N, v): \nexists y \in X(N, v): E(y) \prec_{\text {lex } \min } E(x)\right\}
$$

The following recursive procedure is used to characterize the nucleolus. By definition, $E_{1}(x)$ is the largest excess of any coalition relative to $x$. At the first step of the procedure we find the set $X_{1}$ of all imputations $x$ that minimizes $E_{1}(x)$ :

$\min \epsilon$

s.t. $e(S, x) \leq \epsilon$ for all $S, \emptyset \nsubseteq S \nsubseteq N$.

and $x(N)=v(N)$.

The set $X_{1}$ is called the least core of $c$. If it is not a unique point, we find the set $X_{2}$ of all $x$ in $X_{1}$ that minimizes $E_{2}(x)$, the second largest excess and so on. This process eventually leads to an $X_{k}$ consisting of a single imputation, called the nucleolus (Schmeidler, 1969; Maschler et al., 1979). The nucleolus recursively minimizes the "dissatisfaction" of the worst treated coalitions 23

It has been proved that the nucleolus of a game in coalitional form exists and it is unique. Moreover, if the core is not empty, the nucleolus is in the core (Maschler et al., 2013).

\footnotetext{
${ }^{23}$ Notwithstanding the general recursive definition of the nucleolus, the computation of $X_{1}$ was sufficient in all EU instances, i.e., a single linear program has to be solved. The uniqueness of the solution was verified using the complementary slackness condition.
} 